\title{
Efeito microbicida do leite humano para Escherichia coli
}

\author{
Microbicidal effect of human milk for Escherichia coli
}

Adriana de Melo Fernandes

Aline do Carmo França-BOTELHO

ICentro Universitário do Planalto de Araxá (UNIARAXÁ), Araxál MG - Brasil.

"Centro Universitário do Planalto de Araxá (UNIARAXÁ), Araxál MG - Brasil.
Resumo O leite materno é o melhor alimento para os bebês, provendo nutrição, proteção imunológica e aumentando o laço afetivo entre a mãe e o bebê. Este trabalho objetiva considerar a capacidade bactericida do leite materno para Escherichia coli. Poucos estudos avaliaram aspectos relativos ao armazenamento do leite em refrigerador e congelador e a possível interferência na capacidade microbicida, por isso este estudo tornou-se relevante. O leite materno foi coletado de doadoras com idade entre 18 anos e 35 anos, sendo coletadas amostras de cerca de $12 \mathrm{ml}$ de lactantes em amamentação exclusiva. As amostras foram centrifugadas por 10 minutos para a separação da camada lipídica. Constatou-se que as médias de morte de bactérias foram de $80,3 \%$ para leite refrigerado sem gordura, $70 \%$ para leite congelado sem gordura, e $67,3 \%$ tanto para leite refrigerado e congelado com gordura. Os resultados indicaram que, mesmo armazenado na geladeira, o leite é capaz de matar bactérias, reforçando a importância da prática do aleitamento materno como meio de redução de infecções em lactentes.

Palavras-chave: Leite materno. Escherichia coli. Efeito miCROBICIDA.

Abstract Breast milk is the best food for babies, providing nutrition, immune protection and enhancing the bond between mother and baby. The study proposed to evaluate the bactericidal capacity of breast milk for Escherichia coli. Few studies evaluated aspects related to the storage of milk in the refrigerator and freezer and the possible interference in microbicidal capacity, so this study became relevant. Breast milk was collected from donors aged between 18 and 35 years old, and samples of about $12 \mathrm{ml}$ of exclusively breastfed infants were collected. Samples were centrifuged for 10 minutes to separate the lipid layer. It was verified that the means of death of bacteria were $80.3 \%$ for refrigerated milk without fat, $70 \%$ for frozen milk without fat and $67.3 \%$ for both refrigerated and frozen milk with fat. The results indicated that even when stored in the refrigerator, milk is able to kill bacteria, reinforcing the importance of breastfeeding as a means of reducing infections in infants.

KeY-wordS: BREAST MILK. ESCHERICHIA COLI. MiCROBICIDAL EFFECT. 


\section{INTRODUÇÃO}

O leite materno é, indiscutivelmente, a melhor e mais adequada fonte de nutrientes, fatores de proteção e fortalecimento emocional para o lactente durante o seu primeiro ano de vida. Especialmente quando oferecido como alimento exclusivo até os seis meses de idade, desempenha papel fundamental nas condições ideais de saúde da criança e da lactante, com repercussões favoráveis por toda a vida. ${ }^{1}$

Entretanto, ainda é frequente o desmame precoce e a prática do aleitamento materno ainda está aquém do desejado. Um estudo evidenciou que em grupo de crianças com até 180 dias de idade, a frequência da amamentação foi de $58 \%$ no Brasil. As frequências nas diferentes regiões foram $63 \%, 59 \%, 51 \%, 61 \%$ e $56 \%$, respectivamente para Norte, Nordeste, Sudeste, Sul e Centro-oeste. ${ }^{2}$

Não só no Brasil, mas também em outros países a taxa de abandono do aleitamento materno é significativa. Por exemplo, em Portugal à saída da maternidade, $91 \%$ das puérperas amamentavam o seu filho, sendo $77,7 \%$ amamentação exclusiva. Em três meses, o percentual caiu para $54,7 \%$, e, em seis meses, para $34,1 \%$. As principais causas atribuídas para o desmame foram a hipo ou agalactia, dificuldades na pega e o regresso da mãe ao trabalho. ${ }^{3}$

A amamentação é considerada uma estratégia importante de sobrevivência infantil pelo Fundo das Nações Unidas para a Infância (UNICEF), pela Organização Mundial da Saúde (OMS) e por vários órgãos de proteção à criança. A proteção conferida pelo leite humano contra infecções comuns em crianças repercutiu na redução da mortalidade infan- til. Cerca de $13 \%$ a $15 \%$ de todas as mortes de crianças abaixo de 5 anos de idade em todo o mundo, sendo $50 \%$ por doenças respiratórias e $66 \%$ por diarreia, poderiam ser prevenidas com o aleitamento materno. ${ }^{4}$

Há vários elementos imunologicamente competentes presentes no leite humano, entretanto, o anticorpo IgA merece especial destaque. Ele é a imunoglobulina com maior capacidade protetora nas mucosas intestinal e respiratória. O leite materno também possui outras imunoglobulinas, oligossacarídeos, lipídeos, peptídeos bioativos, entre outros constituintes, com mecanismos que, além da proteção contra doenças, estimulam o desenvolvimento do sistema imune do lactente. ${ }^{5}$

Os peptídeos antimicrobianos derivados do leite têm inibido muitos patógenos Gram positivos e Gram negativos, incluindo Escherichia coli, Aeromonas hydrophila, Salmonella typhi, Bacillus cereus, Salmonella typhimurium, S. enteritidis, Staphylococcus aureus. ${ }^{6,7}$

A bactéria Gram-negativa E. colié a mais comum e clinicamente importante espécie do gênero Escherichia. Esse microrganismo está associado a uma variedade de doenças, incluindo gastroenterite, meningite, infecção das vias urinárias e sepse. As estirpes de E. coli enteropatogênicas (EPEC) são importantes causas de doença diarreica aguda em crianças menores de 5 anos de idade na América Latina, África e Ásia, e estão associadas à alta mortalidade em crianças de comunidades mais carentes. ${ }^{8}$

Os benefícios do aleitamento materno são amplamente difundidos. Há estudos que mostraram diversas ações microbicidas para patógenos de importância para a pediatria. ${ }^{6,7,9,10}$ Entretanto, aspectos relativos ao 
armazenamento do leite em refrigerador e congelador, considerando uma possível interferência na capacidade microbicida, ainda não são amplamente conhecidos. Diante disso, este estudo tornou-se relevante, objetivando o conhecimento de tais variáveis quanto à ação bactericida do leite para $E$. coli, importante patógeno diarreiogênico em crianças.

\section{Metodologia}

A pesquisa foi desenvolvida na cidade de Araxá, Minas Gerais, Brasil. A abordagem das doadoras, bem como, a coleta de leite ocorreram nos seguintes locais: Unidade Básica de Saúde (UNISA) e Hospital Regional Dom Bosco de Araxá (MG), conforme autorização prévia dos responsáveis. Cada mãe doadora assinou um Termo de Consentimento Livre e Esclarecido.

O projeto foi aprovado pelo comitê de ética em pesquisa do Centro Universitário do Planalto de Araxá (UNIARAXÁ), protocolo $\mathrm{n}^{\circ}$. 030677/ 50 e seguiu a Resolução 466/12, do Conselho Nacional da Saúde. Para a escolha das doadoras, foram obedecidos os seguintes critérios: idade entre 18 anos e 35 anos; idade gestacional entre 38 a 41 semanas; recém-nascidos com peso adequado à idade gestacional.

Foram coletadas amostras de cerca de $12 \mathrm{ml}$ de três lactantes em amamentação exclusiva. Metade da amostra foi usada para teste direto e metade foi centrifugada a 160 $\mathrm{x} g$, por 10 minutos, para descarte de camada lipídica. ${ }^{9}$

O tempo de armazenamento foi de duas horas, para cada amostra de leite conseguiram-se quatro alíquotas, sendo que $25 \mu \mathrm{de}$ cada uma foram colocados em placa de poços de cultura celular, com o mesmo volume de cultura de E. coli (EPEC) em meio líquido TSB ( $1 \times 10^{6}$ bactérias por $\left.\mathrm{ml}\right)$. Foram 12 análises, conforme delineamento: leite refrigerado sem separação de camada lipídica; leite refrigerado com separação de camada lipídica; leite congelado sem separação de camada lipídica; leite congelado com separação de camada lipídica.

Após incubação de duas horas, foi feita lâmina acrescentando uma gota de acridine orange para verificação de viabilidade das bactérias em microscópio de fluorescência. Em pH neutro acridine orange pode ser usado como corante vital, bactérias viáveis coram em verde e não viáveis em laranja. ${ }^{11}$

Após os experimentos, foi feita análise estatística com os softwares Excel e GraphPad InStat (3.0 for Windows). Utilizou-se a análise de variância com os respectivos desdobramentos das interações entre os fatores. Depois de verificar a significância dos fatores estudados, foi realizado o teste de Tukey, para comparação das médias ao nível de 0,05 de probabilidade.

\section{RESUlTAdos E DISCUSSÃo}

As membranas mucosas são as principais portas de entrada para os patógenos, portanto, a existência de interações bem-sucedidas entre a imunidade inata e a adaptativa nesses locais é um pré-requisito para o estabelecimento da saúde. O período neonatal é particularmente crítico, pois a exposição aos microrganismos patogênicos coincide com a imaturidade do sistema imune. ${ }^{12}$ Nessa fase, a amamentação é fundamental, pois, o colostro e leite humanos são veículos 
naturais de nutrientes, anticorpos e células imunocompetentes que a mãe transfere para o filho. Os benefícios nutricionais e protetores do aleitamento materno são amplamente conhecidos, no entanto, os mecanismos imunes, especialmente os inatos, permanecem parcialmente compreendidos.
De acordo com a figura 1, os percentuais de morte de bactérias foram de $80,3 \%$ para leite refrigerado sem gordura, $70 \%$ para leite congelado sem gordura, e 67,3\% tanto para leite refrigerado e congelado com gordura.

Figura 1. Percentuais de mortalidade de bactérias Escherichia coli por ação bactericida exercida pelo leite humano.

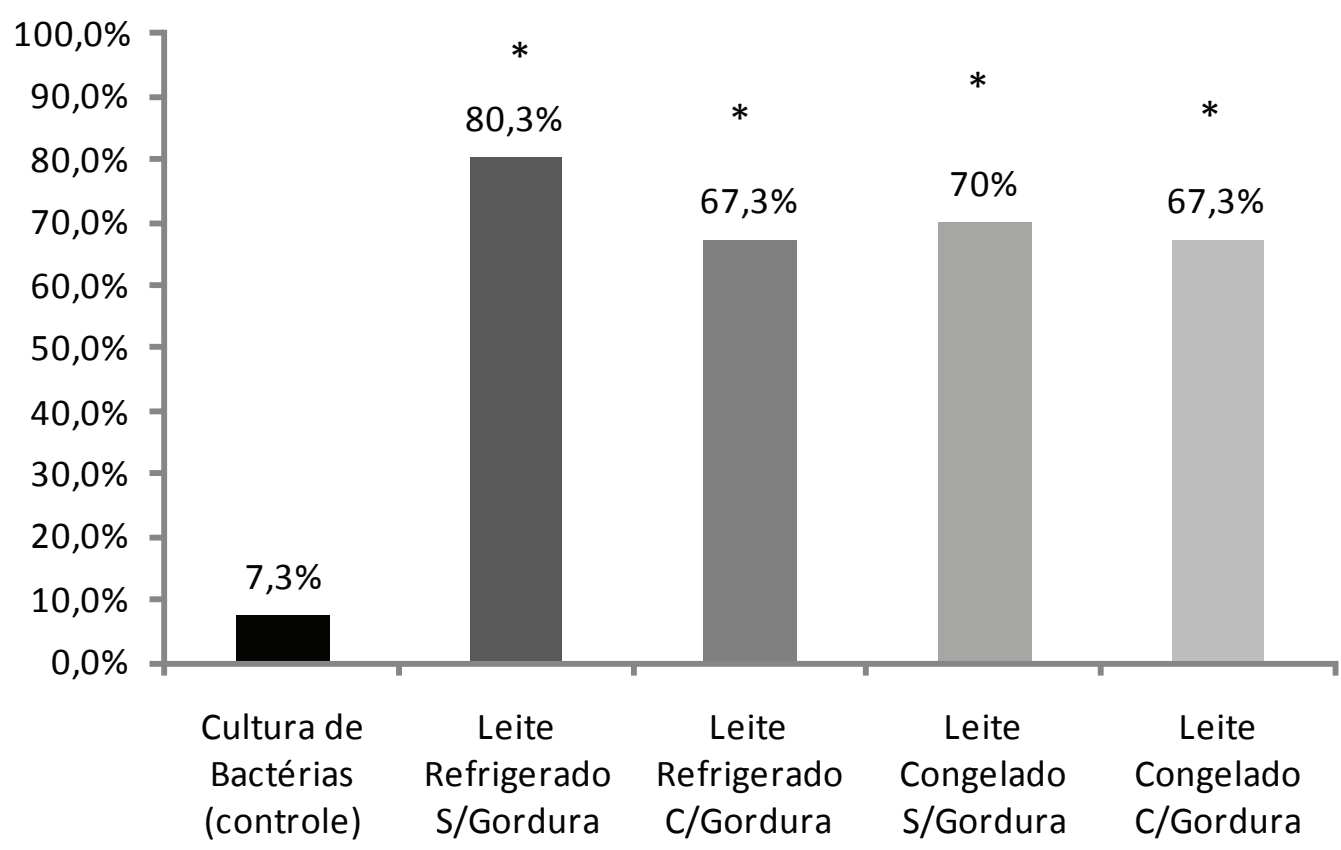

Os resultados expressam a média de três experimentos.

*Indica diferenças estatísticas extremamente significativas em relação ao controle $(\mathrm{P}<0,001)$.

Entre os grupos experimentais (variáveis refrigerado/congelado e com gordura/sem gordura), não houve diferenças estatísticas $(\mathrm{P}>0,05)$.

No estudo realizado por Martínez-Costa et al., ${ }^{13}$ foi demonstrada atividade bactericida média de 83,47\% em amostras de leite materno, média muito similar à obtida neste estudo. Eles também não observaram alterações significativas em razão da refrigeração das amostras.

Assim como no presente estudo, a atividade bactericida foi observada em todas as amostras do estudo de Silvestre et al. ${ }^{14}$ Os testes também foram com E. coli, entretanto, a metodologia foi diferente, pois avaliou o grau de bacteriólise calculado como a diferença entre a contagem de E. coli em controles e em amostras de leite. A atividade manteve-se após refrigeração por até 48 horas e após o congelamento, durante 10 dias, mas mostrou uma diminuição significativa após 
a refrigeração por 72 horas. Eles relatam que a defesa e a proteção contra infecção do recém-nascido podem ser alteradas durante o armazenamento do leite. Por conseguinte, se o armazenamento por mais de 48 horas for necessário, o congelamento é preferível à refrigeração.

Há também relato de que fagócitos do leite humano podem eliminar E. coli enterotoxigênica em presença de sobrenadante rico em $\operatorname{Ig} \mathrm{A}$, indicando que a IgA está envolvida na ação microbicida. ${ }^{15}$ Tal aspecto está de acordo com o fato de que, mesmo sem a camada lipídica, os resultados obtidos nesse estudo foram altamente positivos, reforçando o papel central da IgA do leite quanto à eliminação de patógenos.

Outro estudo ${ }^{9}$ também avaliou a ação microbicida do leite humano, foi quanto à morte de Giardia lamblia pelo colostro humano. Foi verificado que os fagócitos do colostro humano são capazes de ingerir trofozoítos de G. lamblia, especialmente quando em presença de sobrenadante, podendo atuar como células efetoras na proteção do neonato contra a giardíase.

Sabe-se que o leite humano apresenta diversos fatores antimicrobianos e que vários patógenos, especialmente bactérias, podem ser destruídos pelo contato com o leite materno. Nesse contexto, a amamentação desempenha papel relevante e deve ser estimulada, podendo reduzir a morbidade e mortalidade infantil. ${ }^{16,17,18}$ Deste modo, a equipe de saúde tem papel fundamental para o início e manutenção do aleitamento materno, visto que ele está diretamente associado às informações veiculadas durante a gravidez, orientações quanto à técnica correta e apoio nesse processo. ${ }^{19}$

\section{CONSIDERAÇõeS FINAIS}

Neste estudo, tanto o leite refrigerado quanto o leite congelado apresentaram forte ação microbicida para $E$. coli e a quantidade de gordura presente no leite não interferiu nessa capacidade microbicida.

Esses resultados reforçam a importância do leite materno como agente de proteção imunológica. O leite humano teve importante papel microbicida para E. coli e o seu armazenamento em geladeira não reduziu essa ação benéfica.

A prática do aleitamento materno pode ocasionar redução do risco de infecções no lactente e deve ser estimulada, podendo ter um forte impacto positivo na saúde coletiva.

\section{REFERÊNCIAS}

1. Del Ciampo LA, Ferraz IS, Daneluzzi JC, Ricco RG, Martinelli Junior CE. Aleitamento materno e tabu alimentares. Rev Paul Pediatr. 2008. 26(4): 345-9.

2. Wenzel D., Souza SB. Prevalência do aleitamento materno no Brasil segundo condições socioeconômicas e demográficas. Rev Bras Crescimento Desenvolv Hum. 2011. 21(2): 251-8.

3. Sandes AR, Nascimento C., Figueira J., Gouveia R., Valente S., Martins S., Correia S., Rocha E., Silva LJ. Breastfeeding: Prevalence and determinant factors. Acta Med Port. 2007. 20(3): 193200.

4. Duncan BB, Schmidt MI, Giugliani ERJ. Medicina ambulatorial: condutas de Atenção Primária baseada em evidências, 3. ed. Porto Alegre: Artmed, 2004. 
5. Passanha A., Cervato-Mancuso AM, Silva MEM. Elementos protetores do leite materno na prevenção de doenças gastrintestinais e respiratórias. Rev Bras Crescimento Desenvolv Hum. 2010. 20(2): 351-60.

6. Mohanty DP, Tripathy P., Mohapatra S., Samantaray DP. Bioactive potential assessment of antibacterial peptide produced by Lactobacillus isolated from milk and milk products. Int J Curr Microbiol Appl Sci. 2014. 3(6): 72-80.

7. Mohanty DP, Mohapatra S., Misra S., Sahu PS. Milk derived bioactive peptides and their impact on human health - A review. Saudi J Biol Sci. 2016. 23(5): 577-83.

8. Gomez-Duarte OG. Acute diarrheal disease caused by enteropathogenic Escherichia coli in Colombia. Rev Chil Infectol. 2014. 31(5): 577-86.

9. França-Botelho AC, França EL, Honório-França AC, Costa-Cruz JM. Phagocytosis of Giardia lamblia trophozoites by human colostral leucocytes. Acta Paediatr. 2006. 95(4): 438-43.

10. França EL, Bitencourt RV, Fujimori M, de Morais TC, Calderon IM, Honorio-França AC. Human colostral phagocytes eliminate enterotoxigenic Escherichia coli opsonized by colostrum supernatant. J Microbiol Immunol Infect. 2011. 44(1): 1-7.

11. Strugger S. Fluorescence microscope examination of bacteria in soil. Can J Res. 1948. 26(2): 188-93.

12. Brandtzaeg P. Mucosal Immunity: Integration between Mother and the Breast-fed Infant. Vaccine. 2003. 21(24): 3382-8.

13. Martinez-Costa C., Silvestre MD, Lopez MC, Plaza A., Miranda M., Guijarro R. Effects of refrigeration on the bactericidal activity of human milk: a preliminary study. J Pediatr Gastr Nutr. 2007. 45(2): 275-7.

14. Silvestre D., López MC, March L., Plaza A., Martínez-Costa C. Bactericidal activity of human milk: stability during storage. Br J Biomed Sci. 2006. 63(2): 59-62.

15. França EL, Bitencourt RV, Fujimori M, Morais TC, Calderon IMP, et al. Human colostral phagocytes eliminate enterotoxigenic Eschechia coli opsonized by colostrum supernatant. J Microbiol Immunol Infec. 2011. 44(1): 1-7.

16. Albernaz E., Araújo CL, Tomasi E., Mintem G., Giugliani E., Matijasevich A., et al. Influence of breastfeeding support on tendencies of breastfeeding rates in the city of Pelotas (RS), Brazil, from 1982 to 2004. J Pediatr (Rio J). 2008. 84(6): 560-4.

17. Rocha NB, Garbin AJI, Garbin CAS, Saliba O., Moimaz SAS. Estudo longitudinal sobre a prática de aleitamento materno e fatores associados ao desmame precoce. Pesq Bras Odontoped Clin Integr. 2013. 13(4): 337-342.

18. Sankar MJ, Sinha B., Chowdhury R., Bhandari N., Taneja S., Martines J., et al. Optimal breastfeeding practices and infant and child mortality: a systematic review and meta-analysis. Acta Paediatr. 2015. 104(467): 3-13.

19. Aguiar H., Silva A. Aleitamento Materno: A Importância de Intervir. Acta Med Port. 2011. 24(S4): 889-96.

\section{Dados das Autoras}

\section{Adriana de Melo Fernandes}

Bióloga egressa do Centro Universitário do Planalto de Araxá (UNIARAXÁ). Araxá/MG - Brasil. adrimell2010@gmail.com 
Aline do Carmo França-Botelho

Doutora em Ciências pela Universidade Federal de Minas Gerais. Professora do Centro Universitário do Planalto de Araxá. Araxá/MG - Brasil. alinecfb@terra.com.br

Submetido em: 29-1-2016

Aceito em: 28-3-2017 